\title{
Correlation between Ventilation and Brain Blood Flow during Sleep
}

\author{
Teodoro V. Santiago, Eugene Guerra, Judith A. Neubauer, \\ and Norman H. Edelman \\ Department of Medicine, University of Medicine and Dentistry \\ of New Jersey, Rutgers Medical School, New Brunswick, \\ New Jersey 08903
}

bstract. The relationships between brain blood flow (BBF) and ventilation (VI) were studied during sleep in 13 goats. Unilateral BBF was continuously measured with an electromagnetic flow probe; total and regional $\mathrm{BBF}$ were assessed by the radioactive microsphere technique in four animals. Interacting changes in VI and BBF occurred during both slow wave (SWS) and rapid eye movement (REM) sleep. During SWS, significant decreases in VI and increases in arterial $\mathrm{PCO}_{2}$ occurred compared to wakefulness. BBF during SWS correlated linearly with arterial $\mathrm{CO}_{2}$ tension $\left(\mathrm{PaCO}_{2}\right)$; and the relationship was similar to that for awake goats breathing $\mathrm{CO}_{2}$. During REM sleep, VI was significantly less than both the awake (W) and SWS states due principally to a decrease in tidal volume. BBF during REM sleep was significantly and substantially increased compared with both the $\mathrm{W}$ and SWS states; this increase was shared by all brain areas. The increase in BBF during REM sleep was greater than that predicted from changes in $\mathrm{PaCO}_{2}$. In five goats provided with chronic sagittal sinus fistulae, arteriovenous oxygen difference was measured in separate studies and found to be significantly lower during REM sleep compared with W; brain $\mathrm{O}_{2}$ consumption was similar in magnitude in the REM and $W$ states. Thus, the high BBF of REM sleep was also unexplained by an increase of brain metabolic activity.

We conclude that, during SWS, increases in BBF are explained by hypoventilation and hypercapnia. In contrast, during REM sleep, BBF is substantially in excess

Address all correspondence and reprint requests to Dr. T. V. Santiago, Department of Medicine, University of Medicine and Dentistry of New Jersey, Rutgers Medical School, Academic Health Science Center, CN 19, New Brunswick, NJ 08903. 1983.

Received for publication 1 April 1983 and in revised form 29 September

J. Clin. Invest.

(c) The American Society for Clinical Investigation, Inc

$0021-9738 / 84 / 02 / 0497 / 10 \quad \$ 1.00$

Volume 73, February 1984, 497-506 of that expected from $\mathrm{PaCO}_{2}$ or brain metabolism. It is postulated that this excess of BBF during REM sleep could reduce the central chemoreceptor $\mathrm{pH}$ relative to that present in SWS. The combination of reduction of sensitivity to $\mathrm{CO}_{2}$ and lower tissue $\mathrm{PCO}_{2}$ during REM sleep makes it likely that the output of the central chemoreceptors during this state is less than that during SWS and wakefulness. This may contribute to the low tidal volume and respiratory irregularities of this sleep period.

\section{Introduction}

Ventilation and brain blood flow (BBF) ${ }^{1}$ are linked by the role played by each in determining the magnitude of the other. The level of BBF modulates ventilation by controlling the chemical environment of the brain while the end product of ventilation, arterial blood gas tensions, can alter BBF at any given cerebral metabolic rate. This interaction may be of greater importance during sleep since overall ventilatory drive is depressed and $\mathrm{PCO}_{2}$ levels are increased (1-3). Furthermore, cyclic mismatching of $\mathrm{BBF}$ to metabolism could induce oscillations in brain $\mathrm{pH}$ and contribute to the generation of respiratory irregularities such as periodic breathing or apneas, which are frequently described during sleep (4).

Although simultaneous measurements have not been made, previous studies indicate that both BBF and ventilation are altered during sleep. However, disagreement exists on the magnitude and direction of such changes. BBF has been reported to increase $(5,6)$, decrease $(7)$, or remain unchanged $(8)$ during slow-wave sleep (SWS) while one study reported an increase during rapid eye movement (REM) sleep (6). Similarly, studies that have measured ventilation indicate that it decreases during SWS but disagree on the magnitude and direction of ventilatory changes during REM sleep (9).

This study was designed to examine the interrelationships of ventilation and BBF in the sleeping state. Our results indicate

1. Abbreviations used in this paper: $\mathrm{A}-\mathrm{V} \mathrm{O}_{2}$, arteriovenous $\mathrm{O}_{2}$; $\mathrm{BBF}$, brain blood flow; EEG, electroencephalography (phic); EMG, electromyography (phic); EOG, electrooculography (phic); $\mathrm{PaCO}_{2}$, arterial $\mathrm{CO}_{2}$ tension; $\mathrm{P}_{1} \mathrm{CO}_{2}$, brain tissue $\mathrm{PCO}_{2}$; REM sleep, rapid eye movement sleep; SWS, slow-wave sleep; Te, expiratory duration; $\mathrm{Ti}$, inspiratory duration; VT, tidal volume; VT/Ti, mean inspiratory flow rate. 
that the level of ventilation during SWS plays an important role in determining $\mathrm{BBF}$ levels during this period by controlling the magnitude of $\mathrm{PaCO}_{2}$ changes. In contrast, we found that $\mathrm{BBF}$ increases out of proportion to both $\mathrm{PaCO}_{2}$ and brain metabolism during REM sleep; we postulate that this "excessive BBF" may contribute to the generation of the ventilatory characteristics of this sleep period.

\section{Methods}

Preparation of the animals. 13 goats weighing $25-30 \mathrm{~kg}$ were studied. Each animal was surgically prepared in two stages performed at least 1 wk apart under general anesthesia. On the first surgical day, electrodes for monitoring electroencephalographic (EEG), electromyographic (EMG), and electrooculographic (EOG) activity were implanted. The electrodes consisted of stainless steel, self-tapping screws soldered to a No. $267 / 34$ PVC wire. The location of the electrodes is depicted in Fig. 1. EOG electrodes were placed in the roof of the bony orbit in the lateral frontal sinus, EEG electrodes in the floor of the medial frontal sinus and in the parietal and interparietal bone, and paired EMG electrodes were buried in the posterior cervical musculature either in the cleidooccipitalis or rhomboideus cervicis muscles. The electrode wires were soldered into a miniature plug (ITT Cannon, MD1-95L1, ITT, Santa Ana, CA), which was held in place behind the confluence of the two horns by acrylic cement. On the same day, a tracheal fistula was also created as previously described $(3,10)$.

A week later, an electromagnetic flow probe was implanted using a preparation designed to measure BBF continuously in the unanesthetized goat. In the goat, the internal maxillary artery is the main supply of blood flow to the brain as the vertebrobasilar system is vestigial. Thus, a flow probe that measures unilateral BBF with $<5 \%$ contamination by extracerebral flow can be implanted around the internal maxillary artery following a technique that includes ligation and thrombosis of extracerebral branches $(11,12)$. The flow probes were calibrated before implantation using stored human blood with a hemoglobin content of 10 $\mathrm{g} / \mathrm{dl}$; this approximates a goat's normal hemoglobin content that has a lower limit of normal of $8 \mathrm{~g} / \mathrm{dl}$ (13). The goats of the current study had a mean hemoglobin of $7 \mathrm{~g} / \mathrm{dl}$. On the same day, a heat-sealed polyethylene tubing (PE-190) filled with a heparinized solution was advanced into the aorta through one renal artery after unilateral nephrectomy was performed. The catheter was secured to the skin by a specially constructed cutaneous exteriorization button patterned after that designed by Zambraski and diBona (14). The animals were allowed to recover and were kept for the duration of the experiments in stalls provided with a reverse lighting schedule; i.e., the stalls were dark during the day and lit at night. Daily animal care activities including cleaning and feeding conformed to the lighting schedule.

Measurement of regional BBF. In 4 of the 13 goats, total BBF and its distribution were also measured during wakefulness and REM sleep by a radioisotope-labeled microsphere method (15). In addition to the general surgical preparation of the animals described above, a second catheter was inserted into the same renal artery; this catheter was advanced into the left ventricle under pressure-wave guidance, filled with heparinized saline, heat-sealed, and anchored as described earlier for the arterial catheter. During the study, $0.5 \mathrm{ml}$ of a solution containing $\sim 3.0$ $\times 10^{6}$ microspheres of $15 \pm 3-\mu \mathrm{m}$ diam and labeled with ${ }^{141} \mathrm{Ce}$ was injected into the left ventricle of the awake animal, followed by a 3-ml saline flush. For $1 \mathrm{~min}$ before the injection and $2 \mathrm{~min}$ after the injection, arterial blood was withdrawn continuously from the aortic catheter by a withdrawal pump (Harvard Apparatus Co., Inc., S. Natick, MA) at a rate of $13.8 \mathrm{ml} / \mathrm{min}$. During this procedure, BBF was recorded by the flow meter. A second injection of microspheres labeled with ${ }^{85} \mathrm{Sr}$ was made after 1 min of continuous REM sleep was observed. If the REM sleep epoch terminated before the desired arterial blood collection could be made, a third injection of microspheres labeled with ${ }^{46} \mathrm{Sc}$ was made during the next REM sleep epoch of acceptable duration. Studies were not done during SWS because of limitations on the varieties of radioisotopes that could be injected. The animals were then killed, the brain excised, and the total brain weight recorded. The brain was cut into $\sim 120$ equal $1-\mathrm{g}$ segments, care being taken to identify the anatomic location of each segment. Each segment was weighed and counted for radioactivity emitted from the above isotopes in a gamma well counter (Intertechnique CG-30, IN/US, Fairfield, NJ). The energy windows used were: $125-175 \mathrm{keV}$ for ${ }^{141} \mathrm{Ce} ; 414-614 \mathrm{keV}$ for ${ }^{85} \mathrm{Sr}$; and $800-1,500 \mathrm{keV}$ for ${ }^{46} \mathrm{Sc}$. A computer program was used to compensate for overlapping energies. The total weight and radioactivity of the blood samples drawn from the renal artery were also determined. From these data, total and regional BBF during wakefulness and REM sleep were calculated as described by Marcus et al. (15).

Sampling of cerebral venous blood. In 5 of the 13 goats, a chronic sagittal sinus fistula was also created. A hole was drilled into the sagittal sinus during the first surgical day; this was subsequently resealed with sterile bone wax. On the day of the studies that included measurements of cerebral arteriovenous oxygen differences, the bone wax was carefully scraped off and a snugly fitting needle adapter attached to a heparinized catheter was inserted. Sagittal sinus blood samples were drawn simultaneously with arterial blood samples during wakefulness and sleep.

Production and assessment of sleep. Assurance that the animals would not sleep or nap for at least $6 \mathrm{~h}$ before the studies was achieved by using an apparatus specially designed for mild sleep deprivation. The animals wore a denim vest connected superiorly by a rubber spring to a bar running the entire length of the stall. The spring contained an electromagnetic switch activated by tension; such tension was induced whenever the animals sat or lay down. Once activated, the switch triggered an electrical circuit that produced intermittent noise, which ceased only if the animals stood up. Thus, the animals were able to rest or lie down but remained awake during this period. Electrical power to this circuit was controlled by use of a timer switch.

Criteria used for recognition of sleep, wakefulness, or arousal were similar to that used for other species (16). Representative electrometric recordings obtained in the goat during wakefulness and sleep are shown in Fig. 2. The awake stage was defined by an EEG showing low-voltage, fast activity, an EMG showing ample activity, and an EOG depicting random eye movements. SWS was characterized by a diminution in EMG activity, general absence of eye movements, and an EEG that showed large-voltage, slow-wave activity. REM sleep followed an identifiable period of SWS and showed low-voltage, fast EEG activity, absent EMG activity, and intermittent bursts of rapid eye movements on the EOG.

Conduct of the studies. During the study, the tracheal fistula was connected by an adapter to a Rudolph one-way breathing valve. Ventilation was measured by a pneumotachograph (Fleisch, Dynasciences, Blue Bell, PA) positioned in the inspiratory line and connected to a differential pressure transducer (Validyne BC 158, Validyne Engineering Corp., Northridge, CA). Volume calibrations were made with a 1-liter syringe. Expired $\mathrm{PCO}_{2}$ was measured with an infrared $\mathrm{CO}_{2}$ analyzer 

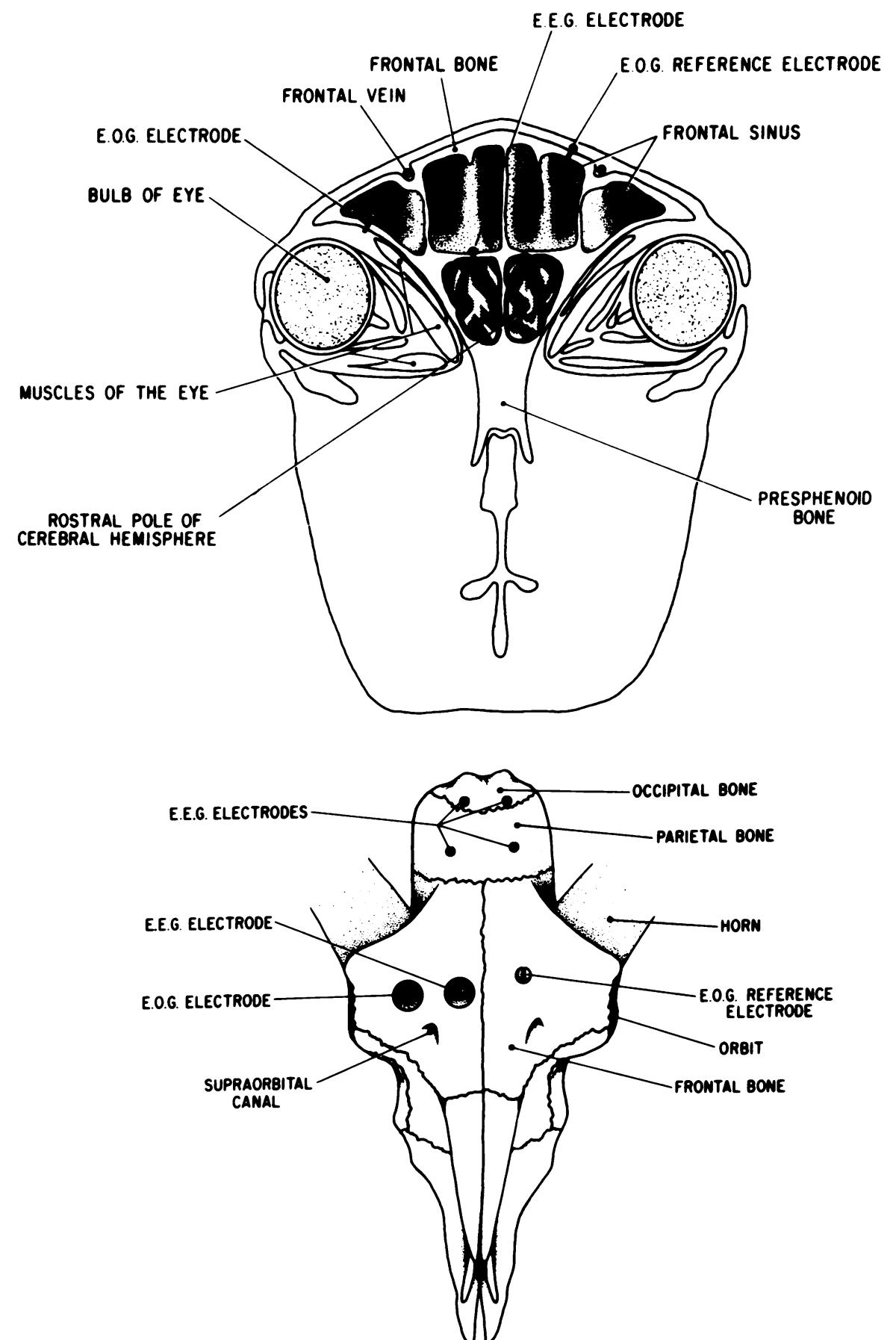

Figure 1. Anatomic placement of electrodes for sleep recordings in the goat. The holes are resealed with acrylic cement.

(Godart Capnograph, Bilthoven, Holland). The goats were anticoagulated (3,000 U heparin, given intravenously) after which the arterial catheter was connected via a needle adapter and stopcock to a blood pressure transducer (Statham P23Db; Statham Instruments, Inc., Oxnard, CA). Arterial blood samples were obtained from this catheter and analyzed for $\mathrm{PO}_{2}, \mathrm{PCO}_{2}$, and $\mathrm{pH}$ by appropriate electrodes (PHM $71 \mathrm{MK} 2 \mathrm{Ra}-$ diometer, America, Inc., Westlake, $\mathrm{OH}$ ) after $6 \mathrm{~min}$ of continuous wakefulness, $4 \mathrm{~min}$ of SWS, and $1 \mathrm{~min}$ of REM sleep during a period of phasic activity. Mean unilateral BBF, ventilation, and the electrometric signals for characterizing sleep or wakefulness were recorded continuously by a Beckman R-612 recorder (Beckman Instruments Inc., Fullerton, CA). 


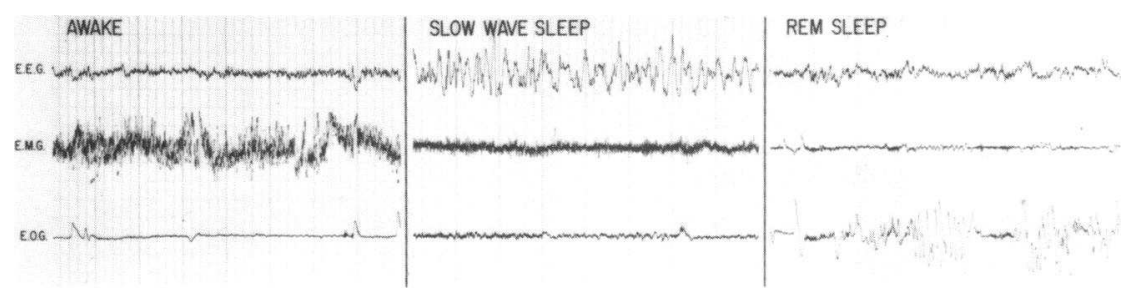

Figure 2. Characteristic electrometric tracing during wakefulness and sleep in the goat.

To determine the effects of sleep on ventilatory and circulatory parameters, the data were analyzed statistically using Freidman's analysis of variance by ranks. Differences between wakefulness and the two sleep stages were determined by the Student-Newman-Keuls test (17).

\section{Results}

The effects of sleep on ventilation and its components in 26 studies of 13 goats are listed in Table I. The data represent the average of all studies. Both SWS and REM sleep are associated with a reduction in minute ventilation $(P<0.05)$ compared with wakefulness. In addition, ventilation was decreased in REM sleep compared with SWS. Tidal volume (VT) was lower $(P$ $<0.05)$ and frequency greater $(P<0.05)$ during REM sleep compared with both wakefulness and SWS. The increase in respiratory frequency during REM sleep was primarily due to a decrease in expiratory duration (Te). Inspiratory duration (Ti) did not change significantly. Arterial blood gas tensions tended to parallel the ventilatory changes. $\mathrm{PCO}_{2}$ was higher and $\mathrm{PO}_{2}$ lower $(P<0.05)$ during both sleep stages compared with the awake values.

BBF changes are also given in Table I. Mean unilateral BBF in 23 studies of 13 goats was $70.7 \pm 3.5$ (SEM) in the awake

Table I. Ventilatory and Circulatory Parameters during Sleep

\begin{tabular}{|c|c|c|c|}
\hline & Awake & SWS & REM \\
\hline V̀I (liter/min) & $4.92 \pm 0.29^{*} \ddagger$ & $4.17 \pm 0.29 * \S$ & $3.68 \pm 0.27 \ddagger \S$ \\
\hline VT (liter) & $0.358 \pm 0.018 \ddagger$ & $0.321 \pm 0.021 \S$ & $0.220 \pm 0.017 \ddagger \S$ \\
\hline$f\left(\min ^{-1}\right)$ & $14.1 \pm 0.8 \ddagger$ & $13.4 \pm 0.8 \S$ & $17.0 \pm 0.8 \mp \S$ \\
\hline $\mathrm{Ti}(s)$ & $1.45 \pm 0.12$ & $1.49 \pm 0.12$ & $1.54 \pm 0.11$ \\
\hline $\operatorname{Te}(s)$ & $3.15 \pm 0.16 \ddagger$ & $3.43 \pm 0.21 \S$ & $2.16 \pm 0.11 \neq \S$ \\
\hline $\mathrm{BBF}(\mathrm{ml} / \mathrm{min})$ & $70.7 \pm 3.5 \ddagger$ & $73.4 \pm 3.3 \S$ & $88.9 \pm 4.8 \ddagger \S$ \\
\hline HR (beats/min) & $91.7 \pm 4.7$ & $90.8 \pm 4.9$ & $90.6 \pm 3.5$ \\
\hline $\mathrm{BP}(\mathrm{mmHg})$ & $89.4 \pm 3.9$ & $87.2 \pm 3.4$ & $92.5 \pm 3.7$ \\
\hline $\mathrm{Po}_{2}(m m H g)$ & $88.0 \pm 1.5 \ddagger^{*}$ & $83.4 \pm 1.8 * \S$ & $76.2 \pm 2.0 \neq \S$ \\
\hline $\mathrm{PCO}_{2}(\mathrm{mmHg})$ & $35.6 \pm 1.0^{*}$ & $37.7 \pm 1.1^{*}$ & $38.9 \pm 1.1 \ddagger$ \\
\hline pH & $7.46 \pm 0.007 \ddagger$ & $7.45 \pm 0.007$ & $7.43 \pm 0.006 \ddagger$ \\
\hline
\end{tabular}

Data presented as mean $\pm \mathrm{SEM}$.

VII denotes minute ventilation; $f$, respiratory frequency; $H R$, heart rate; $\mathrm{BP}$, mean arterial blood pressure.

$* P<0.05$ awake vs. SWS.

$\ddagger P<0.05$ awake vs. REM.

$\S P<0.05$ SWS vs. REM. state. This increased slightly but not significantly to $73.4 \pm 3.3$ $\mathrm{ml} / \mathrm{min}$ during SWS and increased further to $88.9 \pm 4.8$ during REM sleep $(P<0.05)$. Although BBF during REM sleep was always greater than during SWS or wakefulness, the levels were fluctuating; from one to three peaks occurred during a REM epoch. Peaks generally coincided with manifestations of phasic EOG activity. Fig. $3 A$ and $B$ illustrate two patterns of the cerebrovascular responses during REM sleep; one peak occurring in the first pattern and several peaks in the second. The figures also illustrate that the levels of BBF were temporally correlated, in inverse fashion, with VT. The lowest VT that were observed coincided with maximal BBF values.

To determine whether all brain areas shared in the increase of BBF during REM sleep, total BBF and its distribution were measured by the radioisotope technique in four goats. The results listed in Table II indicate that all areas of the brain, including the brainstem, shared in the BBF increase during this sleep stage. Increases in BBF during REM sleep occurred in all four goats. Two of the four goats in this study also had chronically implanted flow probes for BBF measurement. As we have previously reported (18), a good correspondence was found between the radioisotope and flow probe measurements of BBF; means of total BBF being 98 and 110.5 and 158 and $175.5 \mathrm{ml} / \mathrm{min}$ during wakefulness and REM sleep, respectively.

In our attempts to determine the mechanisms involved in the BBF changes during sleep, three possibilities were considered: changes in arterial blood pressure, changes in arterial $\mathrm{PCO}_{2}$, and changes in cerebral metabolic activity. Table I shows that mean arterial blood pressures during both sleep stages were not significantly different from the awake values. Furthermore, Fig. 3 $A$ and $B$ show no temporal correlation between BBF and blood pressure during REM sleep. Thus, we conclude that increase in perfusion pressure was not responsible for the increased BBF during sleep.

To examine the second possibility, we plotted BBF against $\mathrm{PaCO}_{2}$. There were variabilities among goats in the magnitude of base-line BBF, which reflected differences in hemoglobin concentrations and brain weights among the animals. Therefore, absolute values of the two parameters are plotted for each animal in Fig. 4, while grouped responses of the simultaneous changes in each parameter during wakefulness and sleep are shown in Fig. 5. Fig. 4 shows that the levels of BBF during REM sleep were clearly higher, for a given $\mathrm{PaCO}_{2}$ level, than those during SWS. Fig. 5 shows that the increase in BBF when related to $\mathrm{PaCO}_{2}$ during SWS is equal in magnitude to that in our previous 

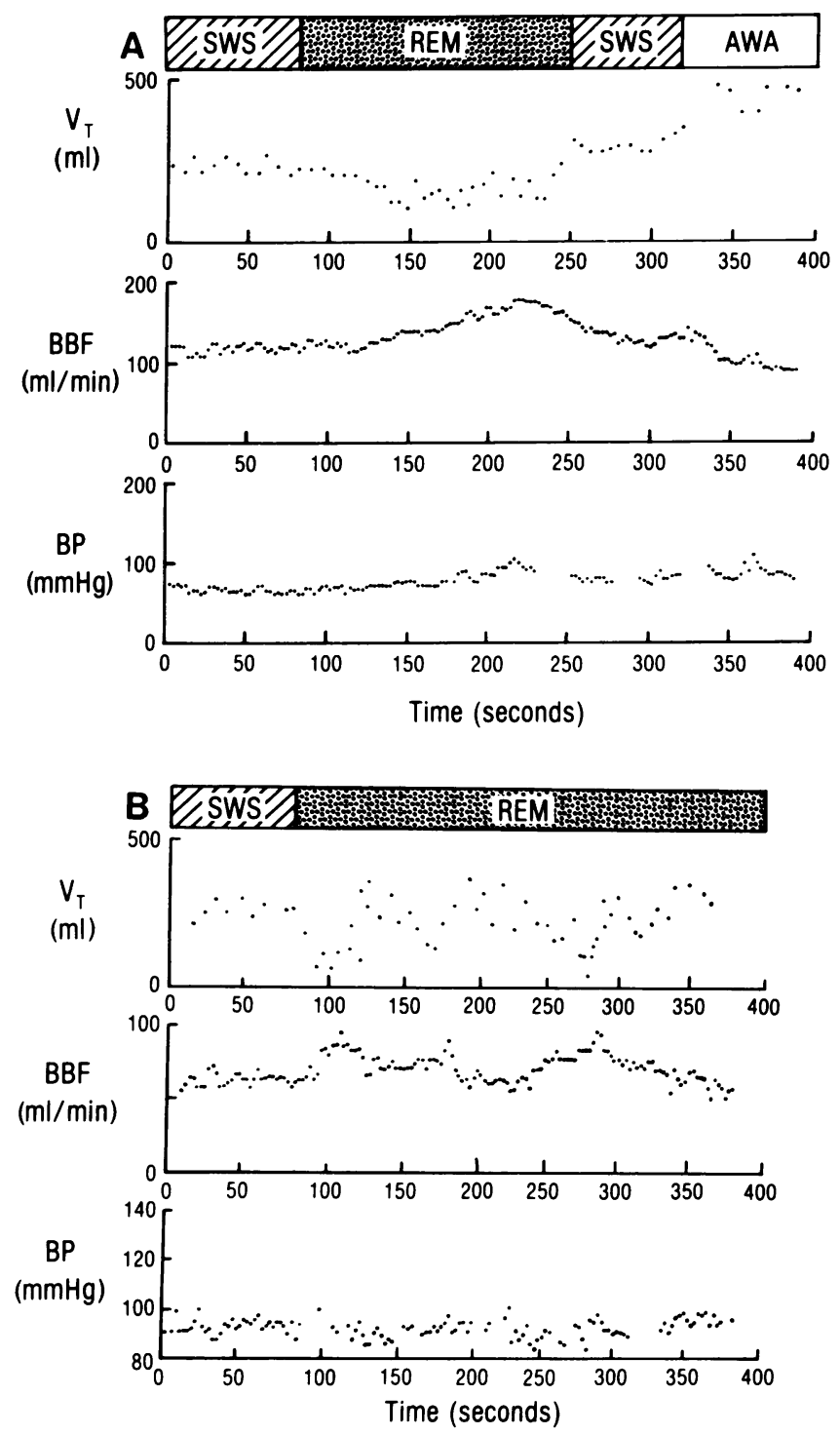

Figure 3. Continuous measurements of VT, BBF, and arterial blood pressure (BP). BBF and VT are inversely correlated; BBF increases as VT decreases during REM sleep. BP does not change systematically $(A)$. Continuous measurements of VT, BBF, and arterial blood pressure. Multiple BBF peaks also occurred during REM sleep. The inverse correlation with VT was largely maintained during such cyclical changes $(B)$

studies of awake goats given $\mathrm{CO}_{2}$ to breathe, averaging $1.6 \mathrm{ml} /$ min per $\mathrm{mmHg}(r=0.866 P<0.01)$ per half-brain in the 13 goats studied. This value is of comparable magnitude to previous reports in dogs (19). The BBF- $\mathrm{PaCO}_{2}$ relationship during $\mathrm{REM}$ sleep was more variable $(r=0.552 P<0.05)$ and greater in slope at $2.79 \mathrm{ml} / \mathrm{min}$ per $\mathrm{mmHg}$. Thus, we concluded that the increase in BBF during SWS, when present, could be explained by concomitant hypercapnia. In contrast, although BBF and
$\mathrm{PaCO}_{2}$ remained linked during $\mathrm{REM}$ sleep, the increase of $\mathrm{BBF}$ in that sleep state seemed out of proportion to the associated hypercapnia.

To determine whether increases in BBF during sleep were related to increases in metabolic rate, cerebral arteriovenous difference for oxygen was measured in separate studies and cerebral metabolic rate for oxygen calculated in five goats (Fig. 6). Since tissue oxygen stores are limited, cerebral arteriovenous $\mathrm{O}_{2}\left(\mathrm{~A}-\mathrm{V} \mathrm{O} \mathrm{O}_{2}\right)$ differences closely reflect the relationship between blood flow and metabolic rate. A decrease in cerebral A-V O indicates that blood flow is disproportionately increased relative to brain metabolic activity. A constant cerebral A-V O $\mathrm{O}_{2}$ in the face of increasing blood flow would indicate that the latter likely occurred in response to the increase in metabolic rate. Fig. 6 shows that cerebral $\mathrm{A}-\mathrm{V} \mathrm{O} \mathrm{O}_{2}$ differences were lower $(P<0.05)$ in REM sleep compared with the awake state suggesting that blood flow was increased out of proportion to $\mathrm{O}_{2}$ consumption. The A-V $\mathrm{O}_{2}$ difference for SWS was not significantly different from the other two states.

The calculated cerebral $\mathrm{O}_{2}$ uptake for the whole brain averaged $4.57 \pm 41 \mathrm{ml} / \mathrm{min}$ in the awake state. This is similar to previously reported values in goats (12). Cerebral $\mathrm{O}_{2}$ uptake during SWS was significantly lower than the awake state $(P$ $<0.05$ ) but not different from REM sleep. Cerebral $\mathrm{O}_{2}$ uptake during REM sleep was similar in magnitude to the waking state. Thus, the high BBF of REM sleep was unexplained by changes in the oxidative metabolism of the brain.

Table III compares cerebral venous gas tension and $\mathrm{pH}$ with these values in arterial blood in the five goats with sagittal sinus fistulae. Cerebral venous $\mathrm{PO}_{2}$ was highest in REM sleep in each animal; cerebral venous $\mathrm{PCO}_{2}$ was lowest during REM sleep in four of the five animals with a resultant mean relative alkalemia. Calculated brain tissue $\mathrm{PCO}_{2}\left(\mathrm{P}_{\mathbf{t}} \mathrm{CO}_{2}\right)$ using the formula of Ponten and Siesjo (20), i.e., $\mathrm{P}_{\mathrm{t}} \mathrm{CO}_{2}=\left(\mathrm{PaCO}_{2}+\mathrm{PvCO}_{2} / 2\right)+1$ showed

Table II. Regional BBF (ml/min per $100 \mathrm{~g})$ in Four Goats

\begin{tabular}{lccl}
\hline & Awake & REM & REM/Awake \\
\hline & & & $\%$ \\
Cortex & & & \\
Cerebellum & $102 \pm 11$ & $158 \pm 24^{*}$ & 155 \\
Thalamus & $99 \pm 11$ & $148 \pm 17$ & 137 \\
Hypothalamus & $84 \pm 10$ & $150 \pm 26$ & 152 \\
Midbrain & $108 \pm 10$ & $126 \pm 19$ & 150 \\
Upper pons & $58 \pm 5$ & $98 \pm 15$ & 169 \\
Lower pons & $66 \pm 5$ & $95 \pm 15$ & 144 \\
Dorsal medulla & $105 \pm 11$ & $135 \pm 23$ & 129 \\
Ventral medulla & $43 \pm 3$ & $58 \pm 4$ & 135 \\
Brain & $99 \pm 10$ & $151 \pm 21$ & 153 \\
& & & \\
\hline
\end{tabular}

Data presented as mean \pm SEM.

$* P<0.05$ for all REM values compared with awake. 

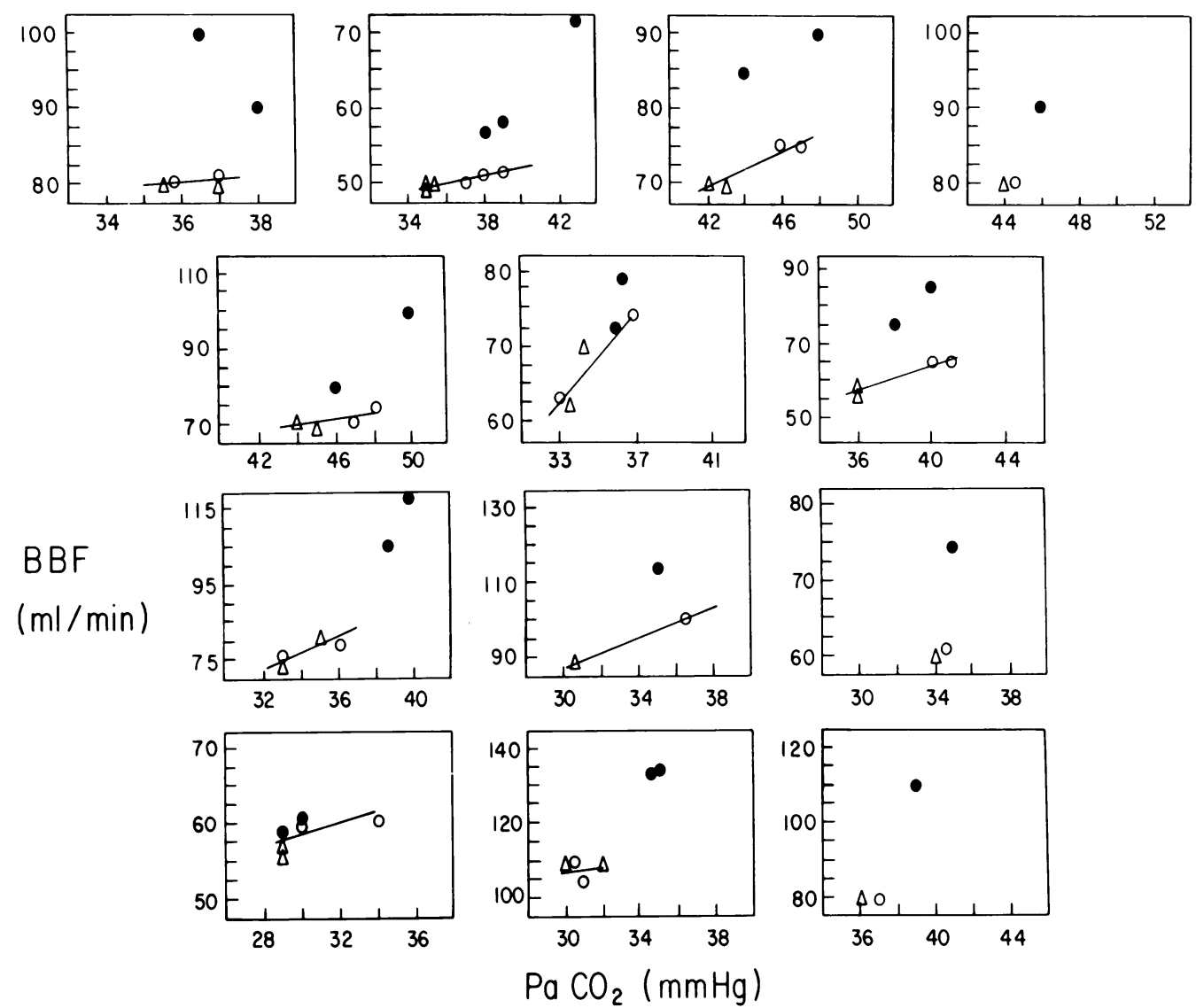

that $\mathrm{P}_{\mathrm{t}} \mathrm{CO}_{2}$ increased in all five animals during SWS compared with the awake state. Calculated mean $\mathrm{P}_{t} \mathrm{CO}_{2}$ was identical during wakefulness and REM sleep.

\section{Discussion}

This study has several findings. First, it indicates that the reduction in ventilation during SWS, and the low tidal volumes and high respiratory frequencies characteristic of REM sleep that have been reported for various species including man (9), are manifested by the goat. Second, it documents changes in BBF in both sleep stages. The data suggest that changes in BBF levels during SWS correlate closely with and can be attributed to the changes in arterial $\mathrm{PCO}_{2}$ level during this sleep period; in contrast, the increase in BBF during REM sleep is unlikely to be solely due to increases in $\mathrm{PCO}_{2}$ nor can it be explained by changes in blood pressure or by an increase in oxidative metabolism. Finally, we found that all areas of the brain, including the brainstem, participate in the marked increase of blood flow during REM sleep.

Ventilatory responses during sleep. There is general agreement that, as found in the current study, ventilation decreases

in the change from wakefulness to SWS (9). Some disagreement exists with regard to the magnitude and direction of changes in ventilation during REM sleep $(21,22)$ but this may merely reflect the unsteady state of ventilation during this sleep period. Our current finding that overall minute ventilation is decreased during REM sleep is in agreement with our previous studies in the cat (3), with the studies of Orem et al. (22) in the same species and with the recent report of Douglas et al. (23) in man. A finding of interest in our study is that the increased respiratory frequency characteristic of REM sleep is primarily due to a reduction in Te. One model of respiratory control (24) suggests, on the basis of studies in anesthetized animals, that respiratory cycle timing is primarily dictated by changes in $\mathrm{Ti}$, with changes in Te occurring only as a reflection of changes in $\mathrm{Ti}$. However, our previous studies (10) as well as those of others (25) have shown that, in unanesthetized awake animals, changes in respiratory rate are frequently caused solely by changes in Te. The observations of this study suggest that the control of respiratory timing during sleep is similar to other unanesthetized states. Finally, since VT decreased during REM sleep and Ti did not change, mean inspiratory flow rate (VT/Ti) was significantly reduced during this sleep period. Since this index correlates with chemical respiratory drive, the finding is con- 


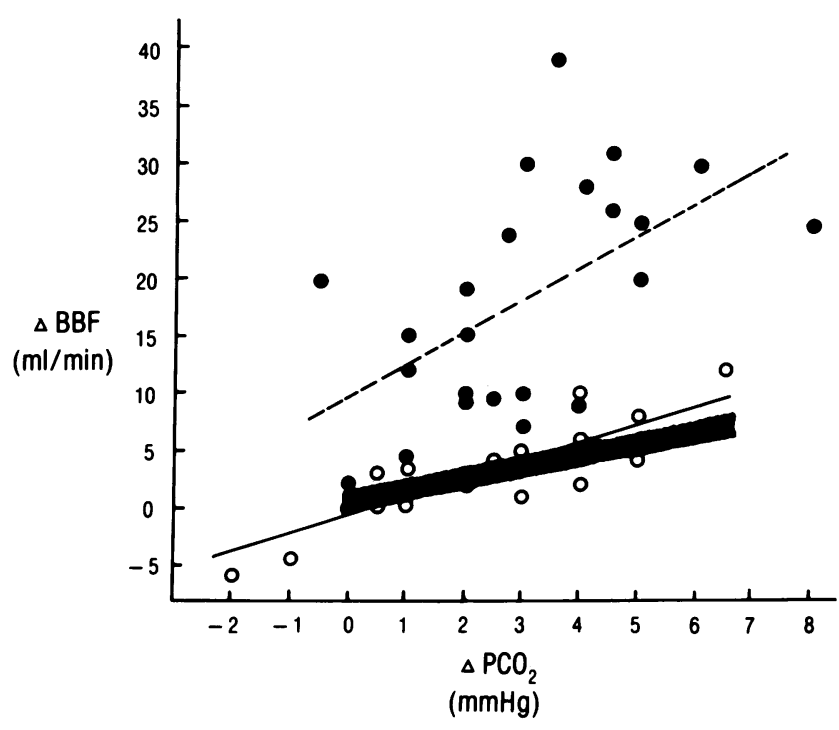

Figure 5. Relationship between changes in unilateral BBF and arterial $\mathrm{PCO}_{2}$ from wakefulness to slow-wave (0) and REM sleep (๑) in 23 studies performed in 13 goats. A direct relationship between the two parameters was found during SWS $(r=0.866)$. During REM sleep, the slope of the regression was greater but the variance was also more $(r=0.552)$. The shaded area represents responses obtained in a previous study from awake goats given $\mathrm{CO}_{2}$ to breathe (18).

sistent with the blunting of chemical drives previously reported during REM sleep (1-3).

$B B F$ responses during sleep. Interest in BBF during sleep dates back to an early hypothesis that the narcosis of sleep is related to brain hypoxia caused by a reduction of BBF (26). The first meaningful study (in light of current knowledge and techniques) was done by Mangold et al. (5) who used the KetySchmidt nitrous oxide method. They reported a $10 \%$ increase in BBF during natural sleep in man, which was not further characterized. In a later study using iodoantipyrine as an indicator, Reivich et al. (6) reported a $15 \%$ increase of BBF during SWS and an $80 \%$ increase during REM sleep in cats. The increase during REM sleep was observed in all brain regions whereas the increase during SWS was shared by only $50 \%$ of the brain areas examined. There were no changes in arterial blood gas tensions in this study; the authors therefore eliminated these factors as possible mechanisms for the increased perfusion. They speculated that the increased BBF during REM sleep was due to increased oxidative metabolism. Similar observations were made by Shapiro and Rosendorff (27) who reported a $25 \%$ hypothalamic blood flow increase during SWS and a $63 \%$ increase during REM sleep, using a ${ }^{133} \mathrm{Xe}$ washout method in rabbits.

In contrast to the above, Risberg and Ingvar (8) reported no changes in BBF during SWS using cortical scintillation counters that quantified intravenously injected ${ }^{131} \mathrm{I}$-labeled serum albumin in man. Townsend et al. (7), using the ${ }^{133} \mathrm{Xe}$ washout technique and therefore probably reporting only on grey matter flow, reported a decrease in BBF of $\sim 14 \%$ during SWS and a modest increase (3-12\%) during REM sleep in man.

Our findings in SWS would seem to reconcile some of the discrepancies regarding BBF during SWS that now exist in the literature, since we found a strong correlation between $\mathrm{PCO}_{2}$ of the arterial blood and BBF. In the seven studies in which $\mathrm{PCO}_{2}$ did not increase during SWS, BBF showed no changes as well. In the two studies where $\mathrm{PCO}_{2}$ decreased during SWS, BBF levels were lower than the awake values. In the remainder both $\mathrm{PCO}_{2}$ and $\mathrm{BBF}$ increased. The magnitude of the relationship between $\mathrm{PCO}_{2}$ and $\mathrm{BBF}$ was similar to that previously described for the awake state and the correlation between the two showed little variance as is illustrated by Fig. 5 . Thus, it seems highly likely that the variability shown by previous studies can be explained by differences in magnitude of ventilation during SWS. In addition, it seems that when increases in BBF occur during SWS they may be attributed to hypoventilation with resultant hypercapnia.

Our studies are also in agreement with previous studies that have shown a significant increase in BBF occurring during REM sleep $(6,27)$. The generalized nature of this increase in brain perfusion suggested by one of these studies (6) is supported by our results as well. We found a significant correlation between $\mathrm{BBF}$ and $\mathrm{PCO}_{2}$ of arterial blood but the slope of the regression was of a substantially greater magnitude and there was much
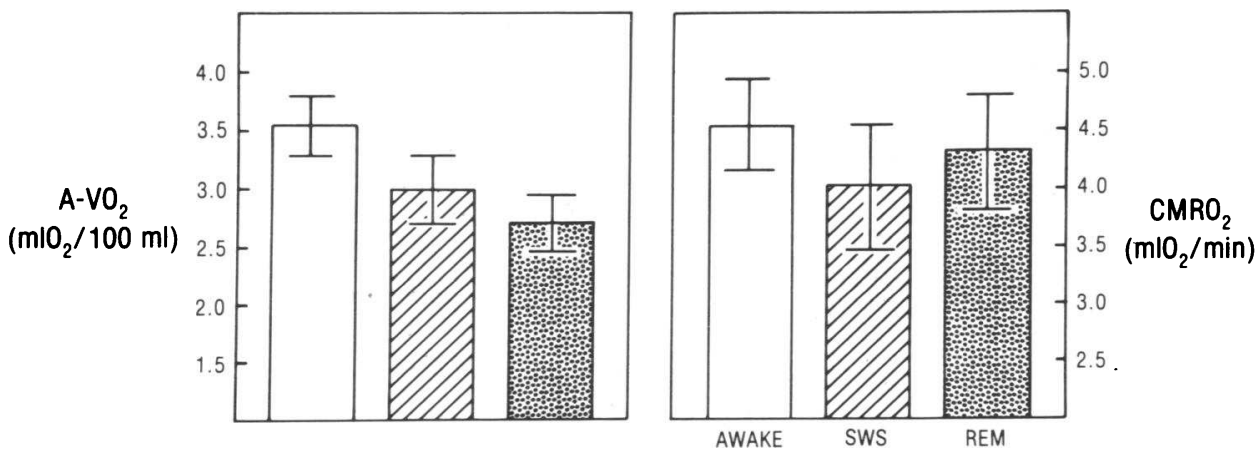

Figure 6. Changes in $\mathrm{A}-\mathrm{V} \mathrm{O}_{2}$ and cerebral oxygen consumption $\left(\mathrm{CMRO}_{2}\right)$ during wakefulness and sleep in five goats. A significant decrease in $\mathrm{A}-\mathrm{V} \mathrm{O}_{2}$ was seen during REM sleep compared with the awake state. 
Table III. Arterial and Cerebral Venous Blood Gas Tensions and pH; Calculated $\mathrm{P}_{t} \mathrm{CO}_{2}$

\begin{tabular}{llllllll}
\hline & $\mathrm{PaO}_{2}$ & $\mathrm{PvO}_{2}$ & $\mathrm{pHa}$ & $\mathrm{pHv}$ & $\mathrm{PaCO}_{2}$ & $\mathrm{PvCO}_{2}$ & $\mathrm{P}_{1} \mathrm{CO}_{2}$ \\
\hline & $m m H g$ & $m m H g$ & & & $m m H g$ & $m m$ & $m m$ \\
Awake & $86.9 \pm 4.2$ & $34.2 \pm 0.9$ & $7.46 \pm .02$ & $7.38 \pm .02$ & $33.7 \pm 1.2$ & $40.0 \pm 1.6$ & $37.9 \pm 1.4$ \\
SWS & $83.4 \pm 4.3$ & $38.2 \pm 1.1^{*}$ & $7.43 \pm .02^{*}$ & $7.39 \pm .02$ & $36.3 \pm 1.6^{*}$ & $40.1 \pm 1.3$ & $39.0 \pm 1.4^{*} \ddagger$ \\
REM & $79.3 \pm 5.5^{*}$ & $41.1 \pm 1.6^{*}$ & $7.43 \pm .02^{*}$ & $7.40 \pm .01$ & $35.2 \pm 1.4^{*}$ & $38.8 \pm 1.4$ & $38.0 \pm 1.4$ \\
\hline
\end{tabular}

Data presented as mean \pm SEM. $\mathrm{PvO}_{2}$, venous oxygen tension. ${ }^{*} P<0.05$ awake vs. SWS or REM. $\ddagger P<0.05$ SWS vs. REM.

more variability of flow. Although mean $\mathrm{PaO}_{2}$ during REM sleep decreased to $76.2 \mathrm{mmHg}$, we do not believe that hypoxia contributed to the BBF changes of REM sleep since BBF responses to hypoxia do not prominently occur above a $\mathrm{PaO}_{2}$ of $50 \mathrm{mmHg}$ (28). Thus, we did not believe that the increase of BBF in REM sleep could be wholly attributed to the concomitant hypercapnia or to the decrease in $\mathrm{PaO}_{2}$ and sought other causes.

In contrast to the speculations of previous workers (6), our data show that an increase in brain oxidative metabolism cannot explain the increase in BBF during REM sleep. The calculated $\mathrm{O}_{2}$ consumption of the brain did not increase and the measured arteriovenous $\mathrm{O}_{2}$ difference actually decreased. The latter is opposite of what would be expected with an increase in metabolism.

After obtaining the above results, we speculated that release of a vasoactive neurotransmitter during REM sleep may be another possible mechanism. We chose to examine possible roles of adenosine, endogenous opioids, and dopamine since they are all putative neurotransmitters that have vasodilatory effects. In three studies, we found that administration of aminophylline in doses of $6 \mathrm{mg} / \mathrm{kg}$ (to block adenosine receptors) and naloxone in doses of $1 \mathrm{mg} / \mathrm{kg}$ (to block endogenous opioid receptors) did not abolish the abrupt rise of $B B F$ measured by the flow probe technique during REM sleep. Representative responses are depicted in Fig. $7 A$ and $B$. Studies with haloperidol (to block dopamine receptors) were equivocal, primarily because of the marked reduction of REM epochs caused by the drug. Therefore, we feel it unlikely that adenosine and endorphins are involved in the cerebrovascular events of REM sleep but dopamine may deserve at least further evaluation. It is, of course, possible that the cerebrovascular phenomenon is yet another manifestation of a breakdown of regulatory mechanisms during REM sleep. Thermoregulation, for example, is known to be impaired during this sleep period (29).

Relation between $B B F$ and ventilation during REM sleep. The significance of the above findings to the control of breathing during REM sleep comes from the observation that the level of BBF is excessive relative to the brain's metabolic needs. This is most clearly demonstrated by the narrowing of the arteriovenous difference for $\mathrm{O}_{2}$ across the brain in that state. Thus, the changes in brain tissue $\mathrm{PCO}_{2}\left(\mathrm{P}_{t} \mathrm{CO}_{2}\right)$ for any given increase in arterial $\mathrm{PCO}_{2}$ are minimized during this sleep period.

If we accept that medullary chemoreceptor responsiveness to $\mathrm{CO}_{2}$ is decreased during REM sleep compared with wake- fulness by at least the same magnitude as that during SWS (2), a lack of increase or a decrease in brain tissue $\mathrm{PCO}_{2}$ caused by the excess BBF of REM sleep could help generate some of the ventilatory characteristics of this sleep period. Our calculations (Table III) indicate that this may occur. In the five animals provided with sagittal sinus fistulae, calculated $\mathrm{P}_{t} \mathrm{CO}_{2}$ was identical during wakefulness and REM sleep and was significantly higher during SWS. Thus, a combination of reduced responsiveness to $\mathrm{CO}_{2}$ and lack of increase in tissue $\mathrm{CO}_{2}$ tension (in contrast to SWS) would render the overall output of the central chemoreceptor least in REM sleep compared with SWS and wakefulness.

The close temporal association of increased $\mathrm{BBF}$ and decreased tidal volume during REM sleep (Fig. $3 A$ and $B$ ) becomes of special interest, therefore. The central chemoreceptors are known to primarily regulate tidal volume $(30,31)$; a low tidal volume, such as was found in this study, is typically found during REM sleep (9). In addition, mean inspiratory flow (VT/ $\mathrm{Ti})$, which is felt by many to closely correspond to overall chemical ventilatory drive, was significantly reduced during REM sleep in this study. Thus, the ventilatory characteristics of REM sleep are consistent with decreased activity of central chemoreceptors and, as outlined above, our data suggest that the output of the central chemoreceptors should be least in this state. It is recognized that the differences in calculated tissue $\mathrm{CO}_{2}$ tension are small. However, the high sensitivity of the central chemoreceptors to small changes in $\mathrm{pH}$ is well documented by the elegant studies of Fencl et al. (32). We estimate from those data, for example, that a change of tissue $\mathrm{PCO}_{2}$ of $1 \mathrm{mmHg}$ would change ventilation by $\sim 30 \%$ in an awake goat.

We do not mean to imply from the above that all of the ventilatory characteristics of REM sleep can be attributed to a relative reduction of central chemoreceptor $\mathrm{PCO}_{2}$. Neural changes, which may be related to the ponto-geniculo-occipital (PGO) waves of REM sleep, for example, may contribute directly or indirectly to the observed respiratory changes by modifying the integration of chemoreceptor response. However, we speculate that the apparent lack of chemical respiratory drive during this period may in part reflect a lower central stimulus. It is interesting to note in this regard the findings of Sullivan et al. (33) that ventilatory responses to $\mathrm{CO}_{2}$ were lower in phasic than in tonic REM sleep. In the present study, BBF levels were highest during manifestations of phasic activity. 


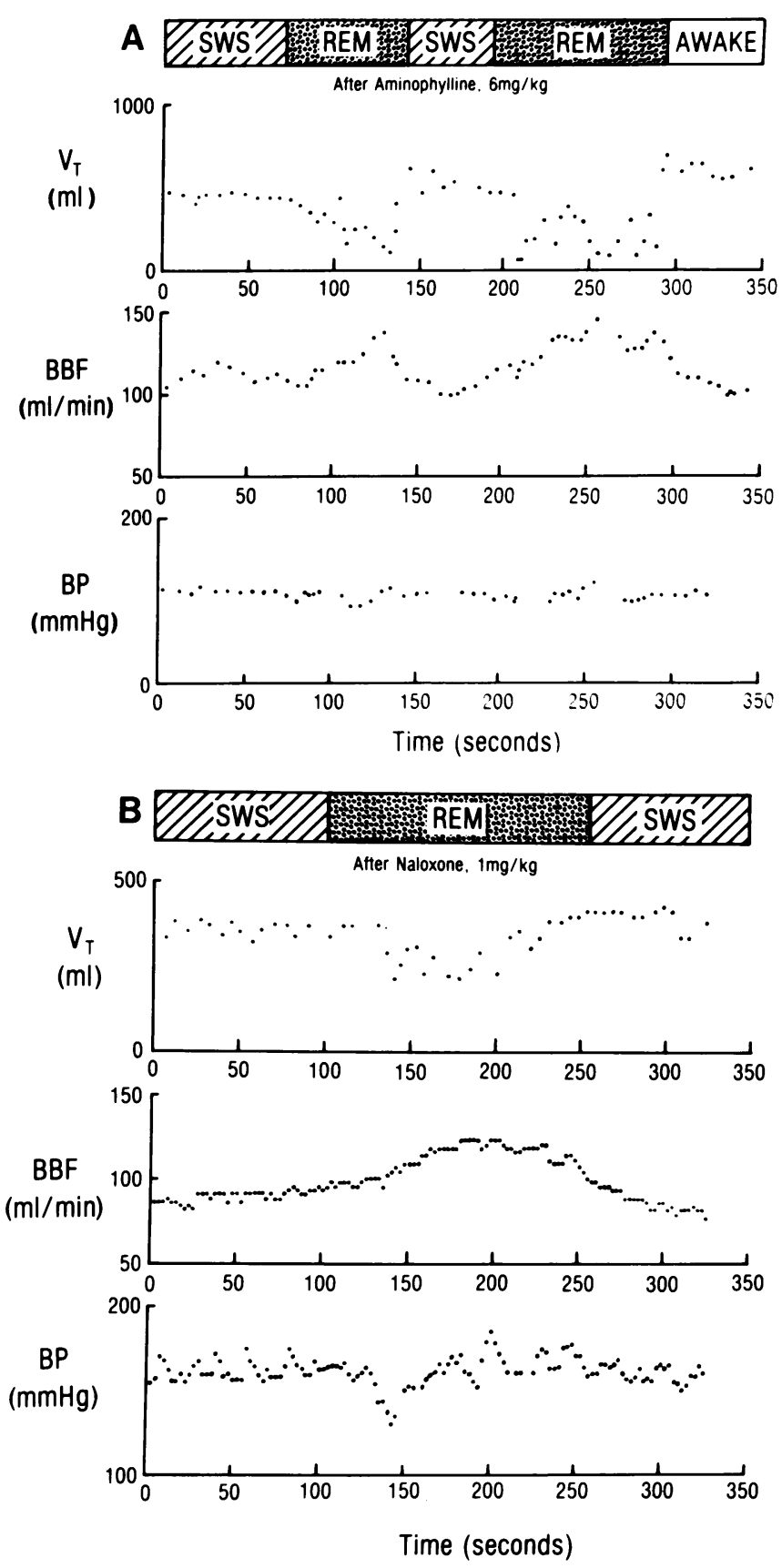

Figure 7. Continuous measurement of VT, BBF, and arterial blood pressure (BP). Naloxone in doses of $1 \mathrm{mg} / \mathrm{kg}$ given intravenously failed to affect both the increase in BBF and the decrease in VT during REM sleep $(A)$. Aminophylline in doses of $6 \mathrm{mg} / \mathrm{kg}$ failed to affect the VT and BBF changes that occurred during REM sleep $(B)$.

Finally, it should be noted that the increase of BBF during REM sleep was not constant but tended to oscillate (Fig. 3). This observation suggests that brain tissue $\mathrm{PCO}_{2}$ oscillates during
REM sleep as well. The latter is of interest in view of the welldocumented clustering of respiratory pauses and apneas during this period $(34,35)$. It seems possible to us that under certain conditions (e.g., hyperventilation initiated by hypoxia) the increase in BBF during REM sleep could bring central chemoreceptor $\mathrm{PCO}_{2}$ below its threshold level and cause apnea. Periodic apnea is a regular feature of ventilation during sleep in hypoxic environments.

\section{Acknowledgments}

We are indebted to Dr. Arabinda K. Sinha for his help in developing the methods for monitoring sleep in the goat, to Ms. Karen de Russo and Ms. Oanh Hoang for their expert technical help, to Dr. Ronald Cody for his statistical advice, and to Ms. Marcella Spioch for the preparation of this manuscript.

This study was supported by National Heart, Lung, and Blood Institute research grants HL 16022, HL 23315 and training grant HL 07467.

\section{References}

1. Douglas, N. J., D. P. White, J. V. Weil, C. K. Pickett, R. J. Martin, D. W. Hudgel, and C. W. Zwillich. 1982. Hypoxic ventilatory response decreases during sleep in normal men. Am. Rev. Respir. Dis. 125:286-289.

2. Douglas, N. J., D. P. White, J. V. Weil, C. K. Pickett, and C. W. Zwillich. 1982. Hypercapnic ventilatory response in sleeping adults. Am. Rev. Respir. Dis. 126:758-762.

3. Santiago, T. V., A. K. Sinha, and N. H. Edelman. 1981. Respiratory flow-resistive load compensation during sleep. Am. Rev. Respir. Dis. 123:382-387.

4. Cherniack, N. S. 1981. Respiratory dysrhythmias during sleep. N. Engl. J. Med. 305:325-330.

5. Mangold, R., L. Sokoloff, E. Conner, J. Kleinermann, P. G. Therman, and S. S. Kety. 1955. The effect of sleep and lack of sleep on the cerebral circulation and metabolism of normal young men. J. Clin. Invest. 34:1092-1 100 .

6. Reivich, M., G. Isaacs, E. Evarts, and S. S. Kety. 1968. The effect of slow-wave sleep and REM sleep on regional cerebral blood flow in cats. J. Neurochem. 15:301-306.

7. Townsend, R. E., P. N. Prinz, and W. D. Obrist. 1973. Human cerebral blood flow during sleep and waking. J. Appl. Physiol. 35:620625.

8. Risberg, J., and D. H. Ingvar. 1977. Increase of regional cerebral blood volume during REM sleep in man. In Sleep: Physiology, Biochemistry, Psychology, Clinical Implications. First European Congress on Sleep Research. Karger, Basel. 384-388.

9. Phillipson, E. A. 1978. Control of breathing during sleep. Am. Rev. Respir. Dis. 118:909-939.

10. Chapman, R. W., T. V. Santiago, and N. H. Edelman. 1980. Brain hypoxia and control of breathing: neurochemical control. J. Appl. Physiol: Respir. Environ. Exercise Physiol. 49:497-505.

11. Reimann, C., S. Lluch, and G. Glick. 1972. Development and evaluation of an experimental model for the study of the cerebral circulation in the unanesthetized goat. Stroke. 3:322-328.

12. Doblar, D. D., T. V. Santiago, and N. H. Edelman. 1977. Correlation between ventilatory and cerebrovascular responses to inhalation of CO. J. Appl. Physiol. 43:455-462. 
13. Coles, E. H. 1972. Veterinary Clinical Pathology. W. B. Saunders Co., Philadelphia. 105.

14. Zambraski, E. J., and G. F. diBona. 1976. A device for the cutaneous exteriorization of chronic intravascular catheters. Lab. Animal Sci. 26:939-941.

15. Marcus, M. L., D. D. Heistad, J. C. Ehrhardt, and F. M. Abboud. 1976. Total and regional cerebral blood flow measurement with 7-, 10-, 15-, 25-, and 50- $\mu \mathrm{m}$ microspheres. J. Appl. Physiol. 40:501-507.

16. Ursin, R. 1968. The two stages of slow-wave sleep in the cat and their relation to REM sleep. Brain Res. 11:347-356.

17. Zar, J. H. 1974. Biostatistical Analysis. Prentice-Hall, Inc., Englewood Cliffs, NJ. 151-177.

18. Chapman, R. W., T. V. Santiago, and N. H. Edelman. 1979. Effects of graded reduction of brain blood flow on chemical control of breathing. J. Appl. Physiol.: Respir. Environ. Exercise Physiol. 47:12891294.

19. Alberti, E., S. Hoyer, J. Hamer, H. Stoeckel, P. Packshiess, and F. Weinhardt. 1975. The effect of carbon dioxide on cerebral blood flow and cerebral metabolism in dogs. Br. J. Anesth. 47:941-945.

20. Ponten, U., and B. K. Siesjo. 1966. Gradients of $\mathrm{CO}_{2}$ tension in the brain. Acta Physiol. Scand. 67:129-140.

21. Phillipson, E. A., E. Murphy, and L. F. Kozar. 1976. Regulation of respiration in sleeping dogs. J. Appl. Physiol. 40:688-693.

22. Orem, J., A. Netick, and W. Dement. 1977. Breathing during sleep and wakefulness in the cat. Respir. Physiol. 30:265-289.

23. Douglas, N. J., D. P. White, C. K. Pickett, J. V. Weil, and C. W. Zwillich. 1982. Respiration during sleep in normal man. Thorax. 37:840-844.

24. Clark, F. J., and C. von Euler. 1972. On the regulation of depth and rate of breathing. J. Physiol. (Lond.). 222:267-295.

25. Gautier, H. 1976. Pattern of breathing during hypoxia or hy- percapnia of the awake or anesthetized cat. Respir. Physiol. 27:193206.

26. Mosso, A. 1881. Über den Kreislauf des Blutes in Menschlichen Gehirn. Leipzig, Viit.

27. Shapiro, C. M., and C. Rosendorff. 1975. Local hypothalamic blood flow during sleep. Electroencephalogr. Clin. Neurophysiol. 39:365369.

28. Kogure, K., P. Scheinberg, O. M. Reinmuth, M. Fujishima, and R. Busto. 1970. Mechanisms of cerebral vasodilation in hypoxia. J. Appl. Physiol. 29:223-229.

29. Parmeggiani, P. L., and C. Rabbini. 1967. Shivering and panting during sleep. Brain Res. 6:789-791.

30. Cherniack, N. S., N. N. Stanley, P. G. Tuteur, M. D. Altose, and A. P. Fishman. 1973. Effects of lung volume changes on respiratory drive during hypoxia and hypercapnia. J. Appl. Physiol. 35:635-641.

31. Fitzgerald, R. S. 1973. Relationship between tidal volume and . phrenic nerve activity during hypercapnia and hypoxia. Acta Neurobiol. Exp. 33:419-425.

32. Fencl, V., T. B. Miller, and J. R. Pappenheimer. 1966. Studies on the respiratory response of acid-base balance, with deductions concerning the ionic composition of cerebral interstitial fluid. Am. J. Physiol. 210:459-472.

33. Sullivan, C. E., E. Murphy, L. F. Kozar, and E. A. Phillipson. 1979. Ventilatory responses to $\mathrm{CO}_{2}$ and lung inflation in tonic versus phasic REM sleep. J. Appl. Physiol. 47:1304-1310.

34. Block, A. J., P. G. Boysen, J. W. Wynne, and L. A. Hunt. 1979. Sleep apnea, hypopnea, and oxygen desaturation in normal subjects. $N$. Engl. J. Med. 300:513-517.

35. Guilleminault, C., A. Tilkian, and W. C. Dement. 1976. The sleep apnea syndromes. Annu. Rev. Med. 27:465-484. 